\title{
Design and Fabrication of a Solar Powered Lawnmower with Adjustable Wheels
}

\author{
Akene. A \\ Department of Mechanical Engineering \\ Federal University of Petroleum Resources \\ Effurun, Nigeria
}

\author{
Oghenekohwo. A. P \\ Department of Mechanical Engineering \\ Federal University of Petroleum Resources, \\ Effurun, Nigeria
}

\author{
Oghenevwaire. S. I \\ Department of Mechanical Engineering \\ Federal University of Petroleum Resources \\ Effurun, Nigeria
}

\begin{abstract}
In the development of any machine, the source of power supply for such machine is a very important factor in its design especially in underdeveloped country such as Nigeria. In this study a solar powered lawnmower with adjustable wheels was designed and fabricated. The design is aimed at making lawnmowers readily available for use by fabricating a machine that makes use of solar energy captured from the sun to produce the power needed for cutting to take place. The lawnmower features an adjustable wheel device that enables cutting of grasses at different heights. The machine also has two charging source (electrical and solar) for recharging its batteries. Performance evaluation of the machine was done on three (3) different grass species and the time taken to cut the entire grass field was also recorded. Analysis of the results using ANOVA (Analysis of Variance) statistical tool at $90 \%$ confidence level showed that there exist a statistically significant difference between the grasses and the various heights of the machine studied. The results of the test indicate that the machine performed differently on the three (3) different grasses and has an overall efficiency of $81.67 \%$. Overall, the machine is fast, light weight, easy to operate and very efficient.
\end{abstract}

Keywords: Solar powered, lawnmower, adjustable wheels, rechargeable, grasses

\section{INTRODUCTION}

Grass is a narrow leave (herbaceous plants and monocotyledon plants) that grows from the base and covers the ground in a lawn and other places [10]. Different species of grasses exist in nature; many are short but some plants of the grass family can grow very tall. Grass serve as food source to some organisms and animal, and also provide some of the oxygen man and other living things use up in respiration. However, these grasses can cause serious obstruction and environmental issues if not well maintained. Grass maintenance basically involves cutting and keeping the grass to an acceptable level. In the past, scythe, hand shear and cutlass were used for grass cutting. However, with growing technological advancements, modern ways of cutting grasses emerged. One of such methods is the use of lawnmower.

Lawnmowers have been in existence for a very long time with its first invention dating as far back as 1830 [4]. A lawnmower as defined by [7] is a machine that uses a revolving blade to cut grasses at equal heights. "Reference [5]" also defined a lawnmower as a machine consisting of rotor, motor and blades used to cut grass up to some specific height that can be varied according to the design criteria of the mower blades. Lawnmowers are of different types among which are the hand held mower, walk behind mower, riding mower, the tow behind mower, automatic mower and the solar powered lawnmower, each having its own unique peculiarity in terms of operation, performance, maintenance, cost, etc. In developed countries, lawnmowers are readily available for use owing to the availability of steady power supply. However, in underdeveloped countries such as Nigeria where electricity power supply is very unreliable, coupled with high cost of fuel makes it a luxury to have in most homes.

The sun provides us with an abundant amount of solar energy waiting to be harness and put into use. The concept of solar energy is not a new one but its various applications are and this is due to the unpopularity of its applications resulting from the previously accomplished energy like wood fuels and fossil fuels [11].

This research is focused on developing a solar powered lawnmower that can be adjusted to cut grasses at three (3) different heights as desired by the operator. The machine is also aimed at reducing air and noise pollution as it has no internal combustion engine thus making it a pollution free machine. Lastly, to develop a lawnmower that do not depend on fuel or electricity rather, makes use of solar energy harnessed from the sun.

\subsection{Literature Review}

"Reference [1]" designed a simple self powered lawn mower that is portable and easy to operate. In his design, an alternator for recharging the D. C. battery that powers the electric motor was developed. The blades of the system are driven by multiple pulleys connected to the motor. Overall, it is a cordless electric power mower with $89.55 \%$ cutting efficiency. "Reference [6]" designed and constructed a manually operated cylindrical lawn mower. The mower transfers torque to the blade using an internal 
gear system. Performance evaluation of the machine was done on a sport field and the cutting efficiency of the machine was obtained as $91 \%$ with $0.244 \mathrm{KN}$ human effort. "Refrence [11]" developed a solar mower. A direct current (D.C) motor connected to the battery powers the blades and a photovoltaic panel is use to generate the energy needed to power the mower. Performance evaluation of the design was done on a field capacity of $1.11 \times 10-4 \mathrm{ha} / \mathrm{hr} \mathrm{nm}$ and an efficiency of $93 \%$ was obtained. A rotary lawn mower was designed and analysed by [12]. A new product (simple lawn mower) that is cost effective and simple in design was put forward. The frame and adjustable module were analysed using ANSYS workbench. Results showed that under loading condition, the frame is found to be safe and reliable. "Reference [7]" developed a simulation of an improved solar lawn mower machine. Focus was on improving solar powered lawnmowers by using locally available materials in Nigeria. The efficiency of the lawn mower was suggested to be dependent on the ability of the software to predict the circumstance under which failure is likely to occur. SOLIDWORKS 2014 version and finite element method (FEM) were used to simulate the desired model. "Referenc [5]" reviewed and evaluated three (3) different types (solar, electric and gasoline) of lawnmower and concluded that solar powered lawnmower has over $90 \%$ cutting efficiency, and produces no air pollution or noise as compare to internal combustion engine lawnmowers. They also concluded that the direction of sunlight falling on the solar panel can vary how the system is charged.

\section{MATERIALS AND METHODS \\ 2.1 Design concept}

A functional solar powered lawn mower consists of an electric motor, a battery, frame, deck, charge controller, solar panel, cutter, and the wheels, all working together as a unit to efficiently cut grass. "Fig. 1" shows the various views (front, side, top and isometric view) of the solar lawnmower. The machine battery will be powered by two charging source (solar and AC plug-in) and an adjustable wheel system will be incorporated into the design to enable the machine cut grasses at different heights as preferred by the user.

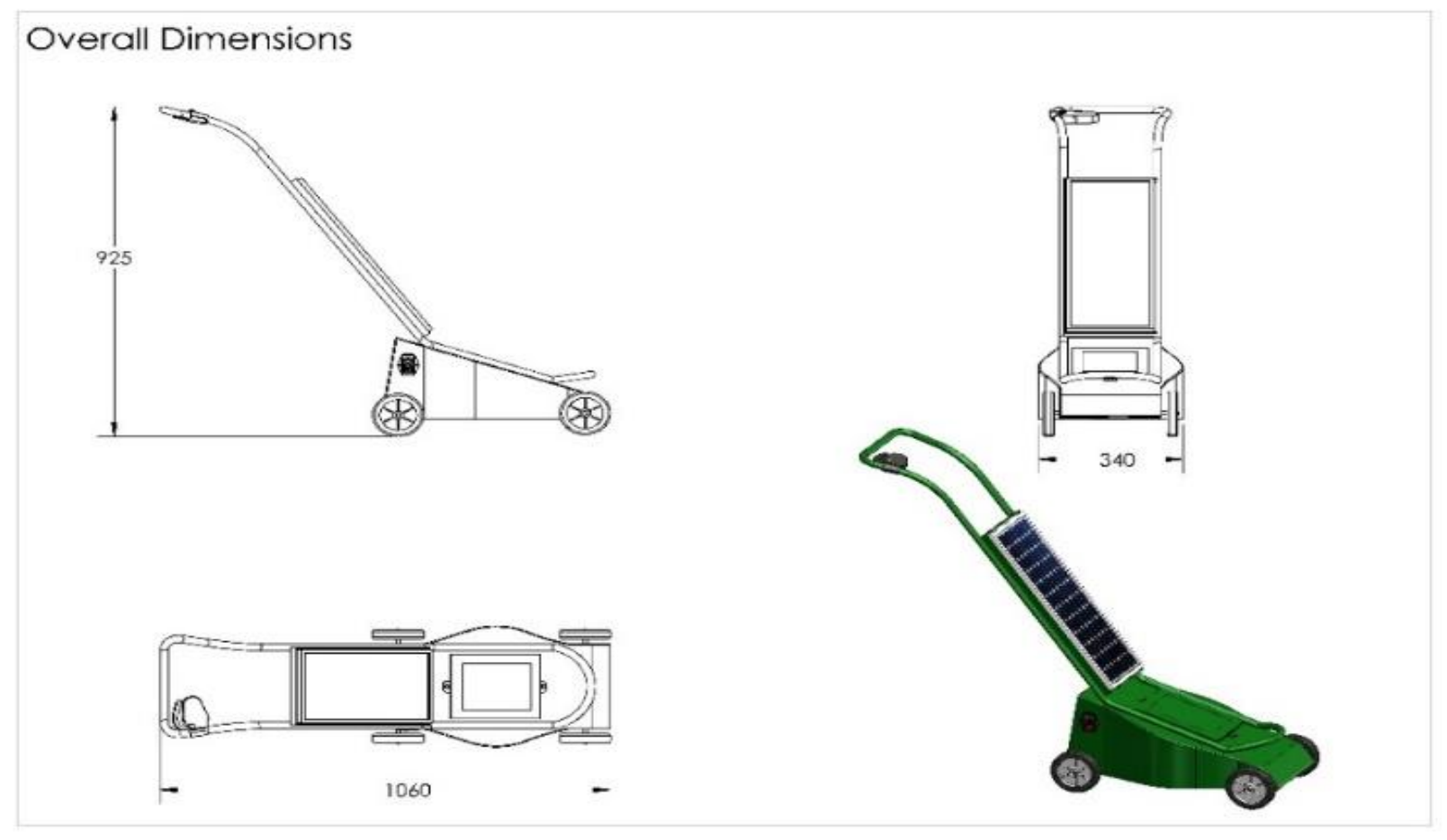

Fig. 1: Different views of the solar lawn mower

\subsection{Design calculation}

In calculating and selecting the appropriate materials for the fabrication and selection of various parts required for the design of the machine, useful mechanical engineering design textbooks were consulted [2] and [9]. In this research, factors such as cost, availability, strength, weight etc were taken into consideration in the selection of various materials of components needed for the design.
Calculating energy generated by the solar panel $(E)$

The energy generated by the solar panel can be estimated using "(1a)" and "(1b)"

$$
\mathrm{E}=\mathrm{A} \times \mathrm{R} \times \mathrm{H} \times \mathrm{PR}
$$

where $\mathrm{A}=$ area of the panel, $\mathrm{R}=$ efficiency of the solar panel, $\mathrm{H}=$ annual average solar radiation on tilted panels $\left(5.535 \mathrm{Kwh} / \mathrm{m}^{2} /\right.$ day) and $\mathrm{PR}=$ performance ratio $(0.75)$ 


$$
\text { But } \quad R=\frac{P}{A}
$$

where $\mathrm{p}=$ power of the panel $(360 \mathrm{w})$ and $\mathrm{A}=$ area of panel,

therefore, “(1a)" becomes

$$
\begin{gathered}
\mathrm{E}=\mathrm{p} \times \mathrm{H} \times \mathrm{PR} \\
\mathrm{E}=360 \times 5.535 \times 0.75 \\
\mathrm{E}=1.494 \times 10^{3} \mathrm{KJ} / \text { day }
\end{gathered}
$$

\section{Torque developed by the motor shaft and cutter}

Torque developed by the cutter can be calculated using "(2)"

$$
\mathrm{T}=\mathrm{WR}
$$

where $\mathrm{W}$ represents weight of the cutter $\left(1.6 \times 10^{-2} \mathrm{~N}\right), \mathrm{R}$ represents the distance from the centre of the hub to the end of the cutter $(0.14 \mathrm{~m})$ and $\mathrm{T}$ represents Torque

therefore,

$$
\mathrm{T}=2.24 \times 10^{-3} \mathrm{Nm}
$$

\section{Power developed by the cutter}

Computing the power developed by the blade by using "(3a)" and "(3b)", where P represents power, T represents torque, $\omega$ represents angular velocity and $\mathrm{N}$ represents Speed transmitted by the motor (10000rpm)

$$
\mathrm{P}=\mathrm{T} \omega \quad \text { "[3]" }
$$

But angular velocity

$$
\begin{gathered}
\omega=\frac{2 \pi N}{60} \\
\omega=\frac{2 * 3.142 * 10000}{60}=1047.33 \mathrm{rad} / \mathrm{s}
\end{gathered}
$$

therefore, $\mathrm{P}=2.24 \times 10^{-3} \times 1047.33=2.514 \mathrm{w}$

$$
\mathrm{P}=0.002514 \times 10^{-3} \mathrm{kw}
$$

\section{Calculating the centrifugal force developed by the cutter}

The centrifugal force is the force produced by the cutter considering the rotational speed of the motor, and can be calculated using "(4)"

$$
\mathrm{F}_{\mathrm{c}}=\mathrm{m} \omega^{2} \mathrm{r}
$$

where $\mathrm{m}$ is mass $\left(1.6 \times 10^{-2} \mathrm{~kg}\right), \omega$ is angular velocity $(1047.33 \mathrm{rad} / \mathrm{s})$ and $\mathrm{r}$ is radius of the cutter $(0.002 \mathrm{~m})$

$$
\begin{gathered}
\mathrm{F}_{\mathrm{c}}=1.6 \times 10^{-2} \times(1047.33)^{2} \times 0.002 \\
\mathrm{~F}_{\mathrm{c}}=35.10 \mathrm{~N}
\end{gathered}
$$

\section{Bending moment of wheel shafts}

Bending moment is the reaction induced on the shaft which causes the shaft to bend when an external force is applied and it's a measure of force and distance from the point of application of the force. The bending moment of the wheel shaft can be calculated with "(5)".

$$
\frac{M}{I}=\frac{\delta b}{y}=\frac{E}{R}
$$

Therefore, $\quad \mathrm{M}=\frac{\delta b * I}{y}$

where $\mathrm{M}$ is moment, $\mathrm{I}=$ moment of inertia, $\delta \mathrm{b}$ is bending stress, $\mathrm{E}$ is young modulus $\mathrm{R}$ is radius of curvature and $\mathrm{y}$ is distance of element from central axis

But

$$
\mathrm{I}=\frac{\pi D^{4}}{64} \text { and } \delta \mathrm{b}=\frac{F}{A}
$$

where $\mathrm{D}$ is diameter $(160 \mathrm{~mm}), \mathrm{F}$ is force $(0.981 \mathrm{~N})$ and $\mathrm{A}$ is area $\left(6384.5 \mathrm{~mm}^{2}\right)$

Thus, $\quad I=\left(3.142 \times(160)^{4}\right) / 64=32 \times 10^{6} \mathrm{~mm}$

And, $\delta b=0.981 / 6384.5=1.54 \times 10^{-4} \mathrm{~N} / \mathrm{mm}^{2}$

Therefore bending moment $\mathrm{M}=\frac{\delta b * I}{y}, \quad$ recall equation (6)

$$
=\frac{1.54 \times 10^{-4} \times 32 \times 10^{6}}{170}=1.123 \times 10^{6} \mathrm{Nmm}
$$

\section{Design calculation of the restraining spring}

The restraining spring is incorporated in the design to aid in holding the wheel shaft in place upon the adjustment of the wheel shaft to the various cutting heights of the design. Selection of the spring was done after considering some factors like the maximum axial force exerted by the wheel shafts on the spring, the maximum shear stress of the spring, etc.

\section{Calculating the maximum force}

Maximum force the spring can undergo without failing can be calculated using "(6)"

$$
\mathrm{F}_{\max }=\mathrm{Ke}=\frac{G d^{4} e}{8 N_{a} D^{3}}
$$

where $F_{\max }$ is maximum force the spring will undergo, $G$ is shear modulus of spring material (200Gpa), D is mean diameter of the spring $(30 \mathrm{~mm}), \mathrm{d}$ is spring wire diameter $(5 \mathrm{~mm}), \mathrm{N}_{\mathrm{a}}$ is number of active coils of spring (4) and $\mathrm{e}$ is extension $(10 \mathrm{~mm})$

$$
\begin{gathered}
\mathrm{F}_{\text {max }}=\frac{200 \times 10^{6} * 5^{4} * 10}{8 * 4 * 30^{3}} \\
\mathrm{~F}_{\text {max }}=1.99 \times 10^{4} \mathrm{~N} / \mathrm{mm}^{2}
\end{gathered}
$$

Calculating the maximum shear stress $\left(\tau_{\max }\right)$ of the spring

The maximum shear stress of the spring can be calculated with "(7)"

$$
\tau_{\max }=\frac{8 W D F_{\max }}{\pi d^{3}}
$$

where W represents wahl's factor, D $(30 \mathrm{~mm})$ and $\mathrm{d}(5 \mathrm{~mm})$ are the mean coil diameter and wire diameter respectively, $\mathrm{N}_{\mathrm{a}}$ (4) represents the number of active coils in this spring and $\mathrm{F}_{\max }\left(1.99 \times 10^{4} \mathrm{~N} / \mathrm{mm}^{2}\right)$ represents the axial force.

But $\mathrm{W}=\frac{4 C-1}{4 C-4}+\frac{0.615}{C}$, where $\mathrm{C}=$ spring index $\left(\frac{D}{d}\right)=\frac{30}{5}=6$ 
Thus, $\quad \mathrm{W}=\frac{4(6)-1}{4(6)-4}+\frac{0.615}{6}=1.2525$

Therefore, $\tau_{\max }=\frac{8 * 1.2525 * 30 * 1.99 \times 10^{4}}{3.142 * 5^{3}}$

$$
\tau_{\max }=1.25 \times 10^{9} \mathrm{~N} / \mathrm{mm}
$$

\section{Battery capacity}

The battery capacity is a measure of the charge stored by the battery and it is determined by the mass of active material present in the battery [8]. This can be calculated using "(8)", where A is current (18A), T is time to charge or discharge battery by half (6hr) and $\mathrm{C}$ is battery capacity.

$$
\begin{aligned}
& \mathrm{C}=\mathrm{AT} \\
& \mathrm{C}=18 \times 6=108 \mathrm{~A}-\mathrm{H}
\end{aligned}
$$

\section{Battery life}

Battery life is the amount of time the device runs before it needs to be charged [8] and it can be calculated with "(9)", where $\mathrm{C}$ represents battery capacity $(108 \mathrm{~A}-\mathrm{H})$, p represents power $(216 \mathrm{w})$, I represents current $(18 \mathrm{~A})$ and $\mathrm{V}$ represents voltage $(12 \mathrm{v})$

$$
\begin{aligned}
& \text { Battery life }=\frac{C * 60 * P}{I * V} \\
& \text { Battery life }=\frac{108 * 60 * 216}{18 * 12}
\end{aligned}
$$

$$
\text { Battery life }=6480 \text { seconds }=1 \mathrm{hr} 48 \mathrm{mins}
$$

\section{Time of charge of battery}

This is the time it takes to charge the battery. The battery charging time is usually dependent on both the charging current and the battery capacity. For this design, the battery will be charged from two sources; the solar panel source and the alternating current (A.C) plug-in.

Charging using solar panel

battery charge time $=\frac{\text { Battery capacity }}{\text { charging current }}$
Given that the battery capacity is 108Ah and the charging current is $12 \mathrm{~mA}$ due to losses

therefore, battery charging time $\quad 108 / 12=9 \mathrm{hrs}$

Charging using A.C plug-in

$$
\text { battery carge time }=\frac{\text { Battery capacity }}{\text { charging current }}
$$

Therefore, battery charge time $=108 / 24=4.5 \mathrm{hrs}$

Thus, it will take 9hrs for the solar panel to fully charge the battery and $4.5 \mathrm{hrs}$ using AC plug-in.

\section{Machine Efficiency}

The efficiency of the machine $\left(E_{m}\right)$ is calculated using " 11 "

$$
\frac{\text { Area of grass cut to desired heights }}{\text { Total area grass field }} \times 100
$$

Therefore, $\quad E_{m}=81.67 \%$

\section{RESULTS AND DISCUSSIONS}

The solar powered lawnmower machine was successfully designed and fabricated. As sunlight falls on the solar panel it is converted to electrical energy and stored in the battery. However, a charger controller is also installed alongside the battery to help prevent overcharging or overdischarging of the battery. The battery therefore transfers the required energy to the electric motor. The electric motor converts the electrical energy into mechanical energy which eventually causes the cutter to rotate thereby producing the required cutting effect on the grass. "Fig. 2" depicts an exploded view of the fabricated solar powered lawnmower machine showing all its parts and the numbers of each part required to fully fabricate and assemble the machine. The fabricated machine after all assembly and painting job has been completed is as shown in "fig. 3". Figure 4a shows the lawnmower height adjustments slots for the wheels while figure $4 \mathrm{~b}$ shows the corresponding heights that the lawnmower wheels can be adjusted to while in operation.

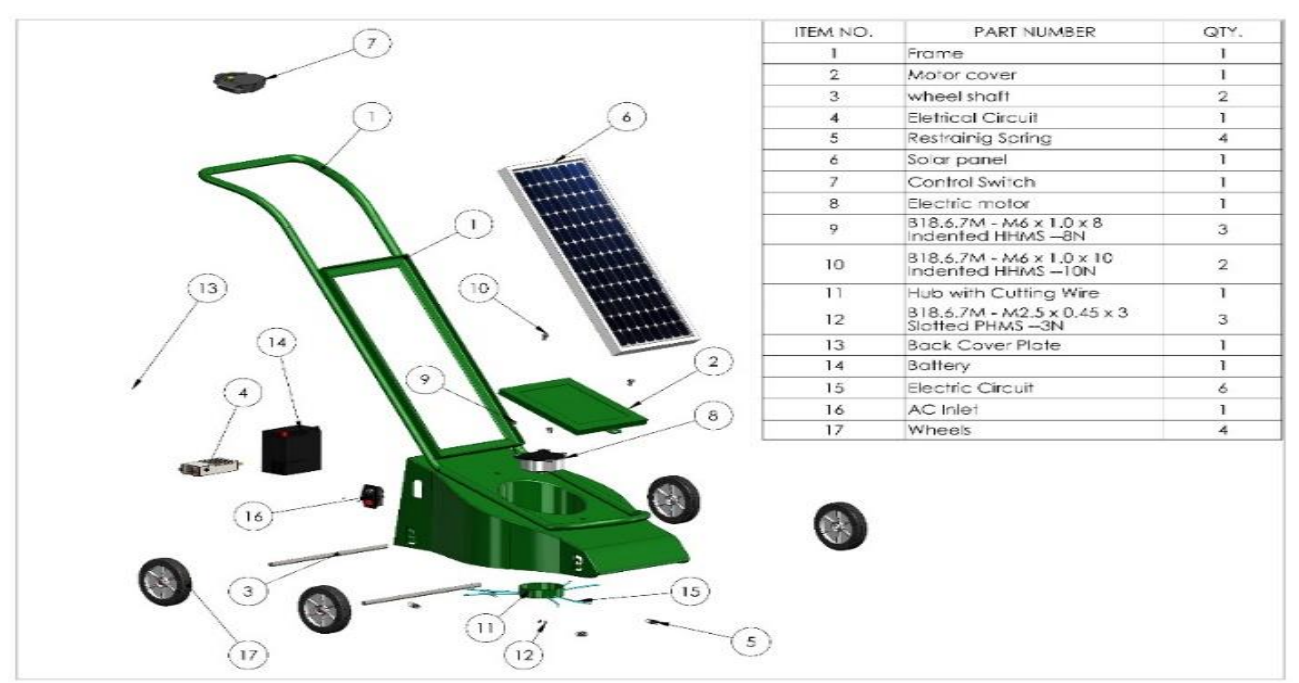

Fig. 2: An exploded view of the solar powered lawnmower 

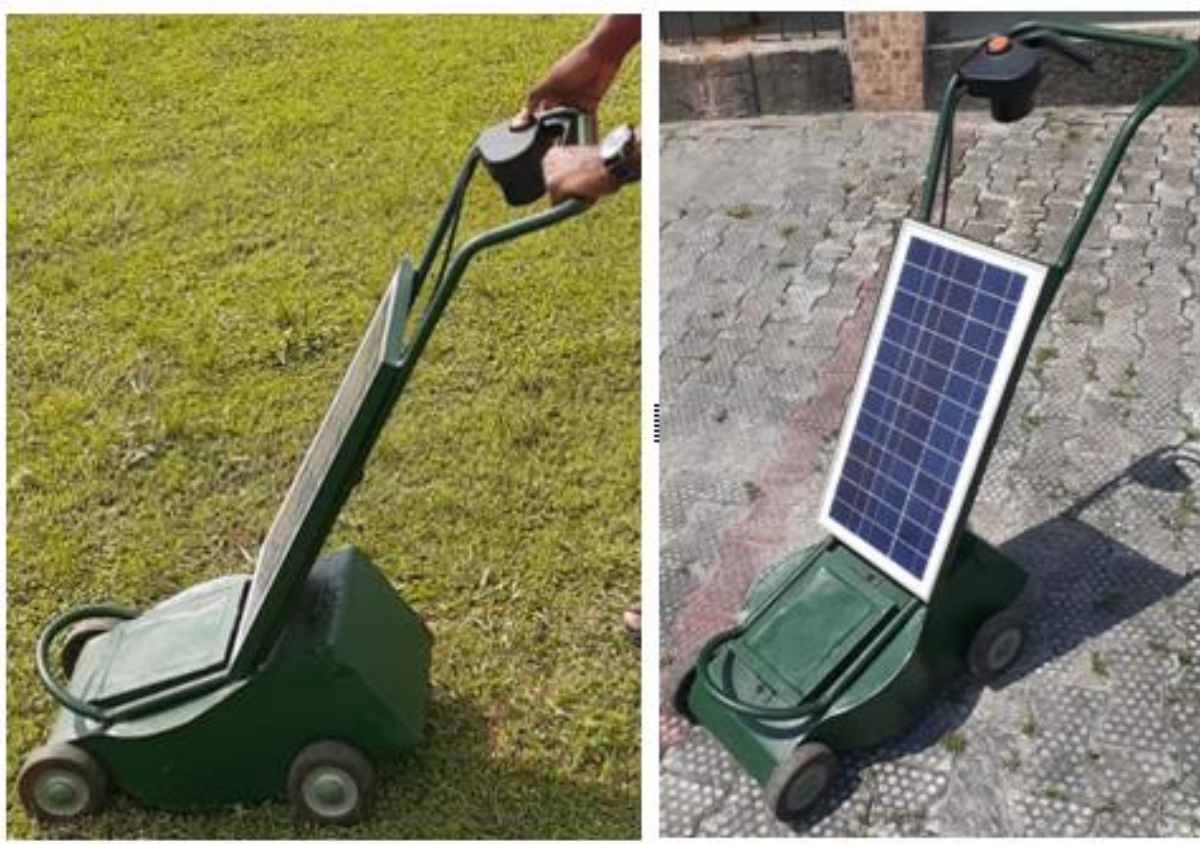

Fig. 3: Fabricated solar powered lawnmower

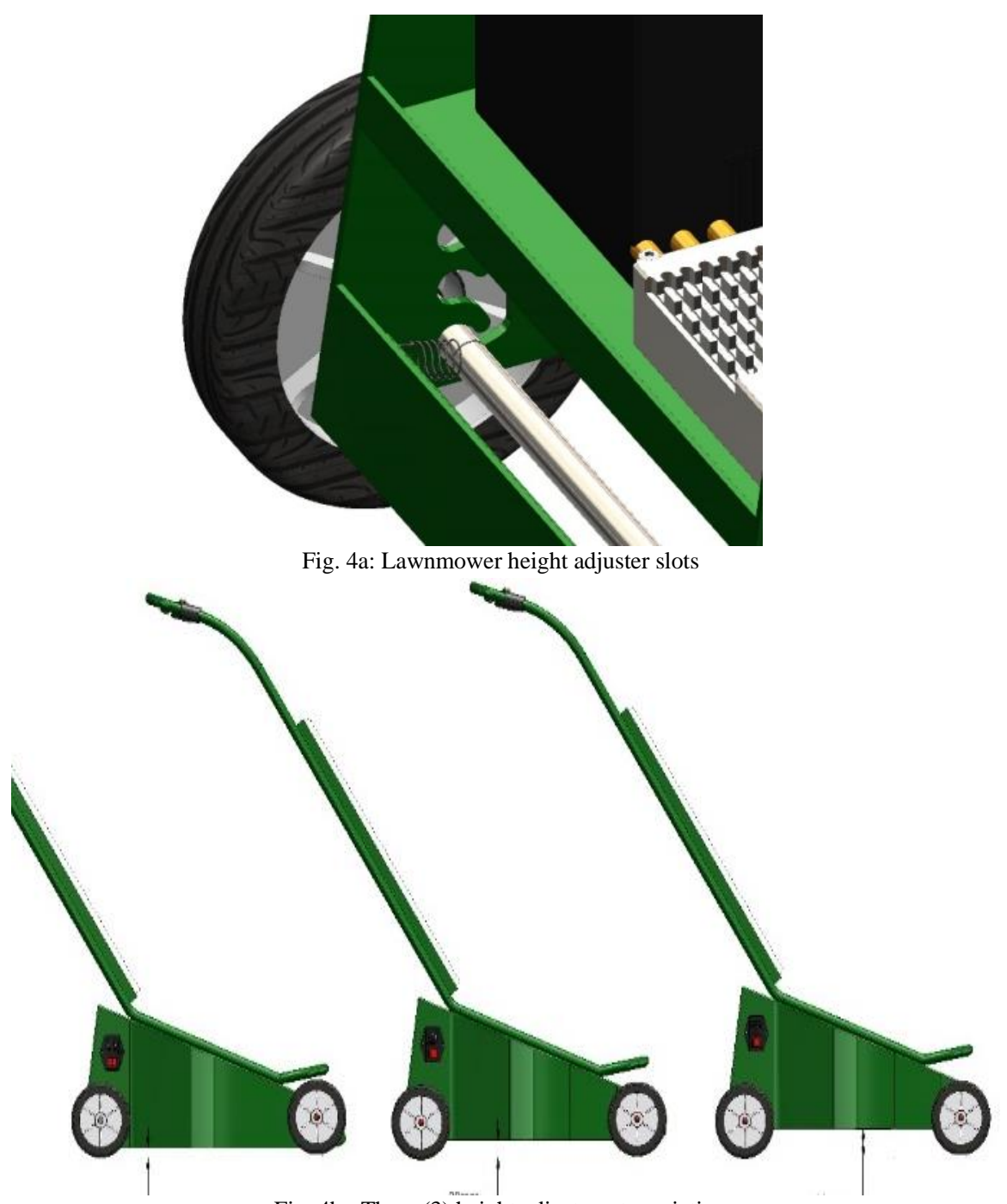

Fig. 4b: Three (3) height adjustments variation 


\section{Performance evaluation}

Performance evaluation of the lawnmower was carried out on three (3) different $3000 \mathrm{~mm}$ by $3000 \mathrm{~mm}$ grass field each containing carpet grass, buffalo grass and elephant grass. All three (3) adjustments level of cuts $(20 \mathrm{~mm}, 70 \mathrm{~mm}$ and $120 \mathrm{~mm}$ ) designed on the lawnmower were tested in all the three (3) grass fields. The time taken to completely cut each of the grass fields was also recorded. Table 1 showed test results obtained from the elephant grass field, while table 2 and 3 showed the results obtained from the buffalo and carpet grass fields respectively. From Table 1, 2 and 3 the average height of grass cut varied slightly from the expected heights designed to be achieved by the machine.

Table 1: Results of elephant grass cutting test

\begin{tabular}{|l|l|l|l|l|}
\hline $\begin{array}{l}\text { Designed cutting height } \\
\text { of machine }(\mathrm{mm}) \\
(\mathrm{Dhom})\end{array}$ & $\begin{array}{l}\text { Average height of un-cut } \\
\text { grass (before cutting) }(\mathrm{mm})\end{array}$ & $\begin{array}{l}\text { Average height of grass } \\
\text { left after cutting }(\mathrm{mm}) \\
(\mathrm{Hgac})\end{array}$ & $\begin{array}{l}\text { Variation from designed } \\
\text { height of machine }(\mathrm{mm}) \\
(\mathrm{Hgac}-\mathrm{Dhom})\end{array}$ & $\begin{array}{l}\text { Time taken to cut } \\
\text { the grass (seconds) }\end{array}$ \\
\hline 120 & 331.60 & 121.89 & 1.89 & 368 \\
\hline 70 & 121.89 & 70.76 & 0.76 & 310 \\
\hline 20 & 70.76 & 21.22 & 1.22 & 266 \\
\hline
\end{tabular}

Table 2: Results of buffalo grass cutting test

\begin{tabular}{|l|l|l|l|l|}
\hline $\begin{array}{l}\text { Designed cutting height } \\
\text { of machine }(\mathrm{mm}) \\
\text { (Dhom) }\end{array}$ & $\begin{array}{l}\text { Average height of un-cut } \\
\text { grass (before cutting) }(\mathrm{mm}) \\
\text { (Hgbc) }\end{array}$ & $\begin{array}{l}\text { Average height of grass } \\
\text { left after cutting }(\mathrm{mm}) \\
\text { (Hgac) }\end{array}$ & $\begin{array}{l}\text { Variation from designed } \\
\text { height of machine (mm) } \\
\text { (Hgac }- \text { Dhom) }\end{array}$ & $\begin{array}{l}\text { Time taken to cut } \\
\text { the grass (seconds) }\end{array}$ \\
\hline 120 & 237.00 & 123.40 & 3.40 & 308 \\
\hline 70 & 123.40 & 71.02 & 1.02 & 263 \\
\hline 20 & 71.02 & 20.15 & 0.15 & 249 \\
\hline
\end{tabular}

Table 3: Results of carpet grass cutting test

\begin{tabular}{|l|l|l|l|l|}
\hline $\begin{array}{l}\text { Designed cutting height } \\
\text { of machine }(\mathrm{mm}) \\
(\mathrm{Dhom})\end{array}$ & $\begin{array}{l}\text { Average height of un-cut } \\
\text { grass before cutting }(\mathrm{mm}) \\
\text { (Hgbc) }\end{array}$ & $\begin{array}{l}\text { Average height of grass } \\
\text { left after cutting }(\mathrm{mm}) \\
\text { (Hgac) }\end{array}$ & $\begin{array}{l}\text { Variation from designed } \\
\text { height of machine (mm) } \\
\text { (Hgac-Dhom) }\end{array}$ & $\begin{array}{l}\text { Time taken to cut } \\
\text { the grass (seconds) }\end{array}$ \\
\hline 120 & 154.20 & 121.17 & 1.17 & 251 \\
\hline 70 & 121.17 & 70.80 & 0.80 & 246 \\
\hline 20 & 70.80 & 20.85 & 0.85 & 239 \\
\hline
\end{tabular}

ANOVA (Analysis of Variance) statistical tool was used to analyze the result obtained. At $90 \%$ confidence level and an alpha level of 0.05 , there exist a statistically significant difference between the grasses and the various heights of the machine studied; Indicating that the lawnmower performed differently at the different level of cutting heights designed for the machine and also on the different species of grass tested. However, the lawnmower's overall efficiency was found to be $81.67 \%$. "Fig. 5" shows a graphical representation of the cutting heights of the three (3) different grasses and the time taken to completely cut each field. At $120 \mathrm{~mm}$ and $70 \mathrm{~mm}$ cutting heights, the elephant grass field took considerable longer time to cut as compared to the buffalo and carpet grass fields. The difference in cutting time observed indicates that the elephant grass is a much tougher grass and requires more energy to achieve, whereas carpet grass are much easier grasses to cut. At $20 \mathrm{~mm}$ cutting heights, the time difference observed between all three (3) grasses is very small, indicating that grasses becomes softer and easier to cut towards the base of the plant.

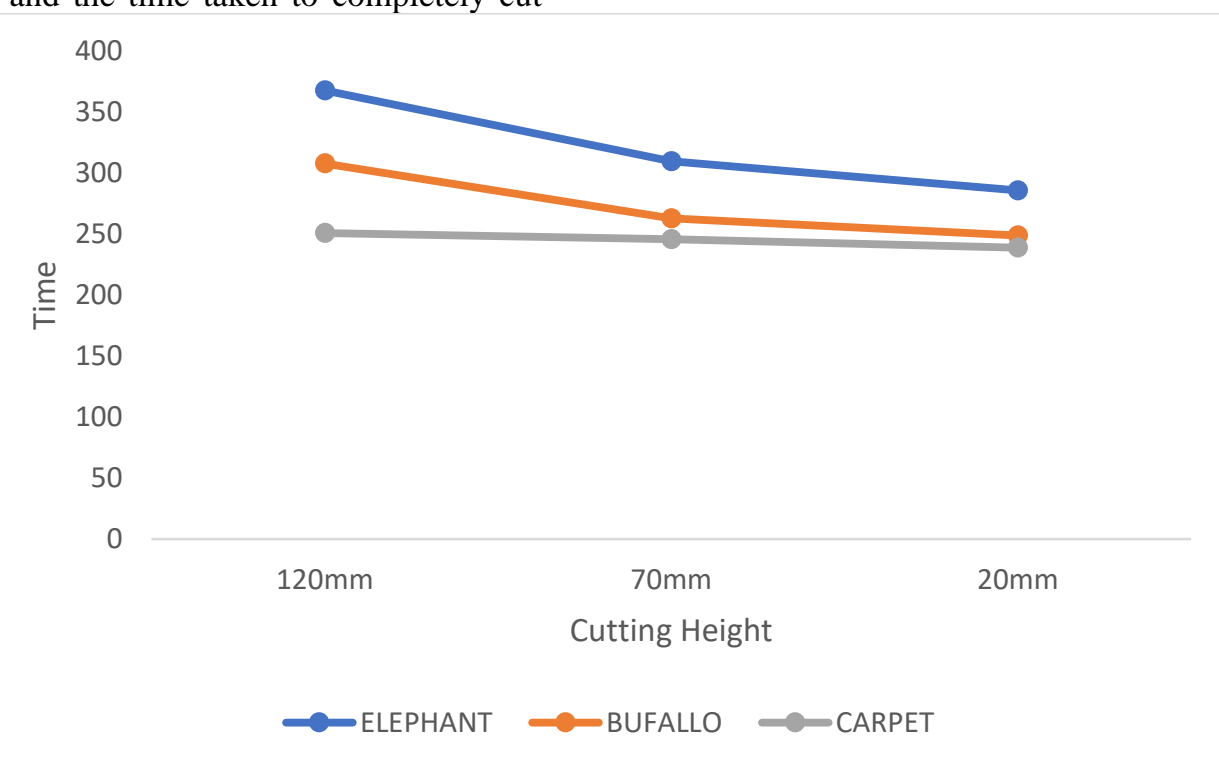

Fig. 5: Graph showing time taken to cut the different types of grasses at different height 


\section{CONCLUSION}

In this study, a modified solar powered lawnmower machine with adjustable wheels was successfully designed, fabricated and tested. The machine is powered by solar energy and can cut grass at three (3) different heights as desired by the operator. Test showed that the lawnmower performed differently on the three grass fields as the time it took to cut each grass varied from one grass to another due to the variation of toughness of the grass species tested. The lawnmower is cost effective in the long run when compared to other type of lawnmowers available in the market and has an efficiency of $81.67 \%$. The lawnmower is pollution free, easy to operate and efficient; however, with the incorporation of better and long lasting batteries, operating time of the lawnmower would be greatly increased.

\section{REFERENCES}

[1] Basil, Okafor (2013). Simple Design of Self-Powered Lawn Mower. Volume 3, 10.

[2] khurmi, R. S., \& Gupta, J. k. (2005). Theory of Machines. New Delhi: Eurasia Publishing ltd.

[3] Khurmi, R. S., and J. K. Gupta. (2011). Text book of Machine design. 8th ed. New Delhi: Euroasia Publishing House PVT, Ltd.

[4] Mabesh, P. (2014). Design and Fabrication of Grass Cutter. Internation Journal for Research in Applied Science and Engineering Technology .

[5] Manpreet, S., Ashutosh, P., Suman, S., Kurman, P., Maushan, R., \& and Tekelllapati, N. (2016). A Review and Comparative Analysis of Solar, Electric and Gasoline Lawnmowers: An Extensive Study. Internetional Journal of Innovative Science, Engineering and Technology .

[6] Okokpujie, I., and Olaseyi, O. K. (2017). Design, Construction of a Cylinder Lawn Mower. Journal of Engineering and Applied Science .

[7] Ogiemudia O. (2015). Design and improvement of a solar powered lawn mower from locally sourced material. Elk asia pacific journal of mechanical enegineering research

[8] Pratik, .P, Ashwini, .B. and Prof. Sheetal, .J, (2014) "Design and Implementation of Automatic Lawn Cutter"International Journal of Emerging Technology and Advanced Engineering, 4 (11), ISSN: 22502459

[9] Richard, G. B. (2010). Shigley's Mechanical Engineering Design. Mcgraw Hill Publisher. USA.

[10] Stichler, C. (2002). Grass growth and Development. Texas Cooperative Extension

[11] Tanimola, O. A., Diabana, P. D., and and Bankole, Y. O. (2014). Design and Development of a Solar Powered Lawn Mower. Vol. 5 (6).

[12] Vivek, P. R., Vishnu, N. V., Akhil, K. A., Kevin, R., and P, a. R. (2016). Design and Analysis of Rotary Lawn Mower. Vol. 5 (04). 